\title{
An Application of Software Engineering for Reading Linear-B Script
}

\author{
Evangelos C. Papakitsos ${ }^{1}$, Argyro Kontogianni ${ }^{2}$, Chrysanthi Papamichail ${ }^{3}$ \& Ioannis K. Kenanidis ${ }^{4}$ \\ ${ }^{1}$ Centre for Counseling \& Vocational Guidance of Elefsina, Greece \\ 2 "Technoglossia" Joint Postgraduate Programme, University of Athens, Greece \\ ${ }^{3}$ Université de Technologie de Compiègne, France \\ ${ }^{4}$ Primary Education Directorate of Kavala, Greece \\ Correspondence: Evangelos C. Papakitsos, Dim. Ralli 28, Athens 11144, Greece. Tel: 0030-226-303-1132.
}

Received: November 3, 2018; Accepted: November 29, 2018; Published: December 7, 2018

\begin{abstract}
Linear-B script has been studied for sixty years since its decipherment. The laborious efforts of the scholars have revealed many linguistic aspects of the oldest known form of Greek (i.e., Mycenaean/Danaic Greek), thus allowing the study of this Indo-European language and its dynamics for thirty-five centuries. In addition, linguistic phenomena closer to the roots of Indo-European languages can be also studied. Yet, the limited usage of LinearB script, merely for keeping records, and its incompatibility to the Greek phonotactics causes misinterpretations of various kinds. The study of Linear-B was not supported till recently by interactive software tools that would facilitate both research and training. Especially for Greek speakers, the resources are even more limited. This paper presents the development of an interactive software system for the study, learning and researching of Linear-B by Greek speakers. This software system is also suggested as a model for the interpretation of other archaic languages.
\end{abstract}

Keywords: computational archaeolinguistics, Aegean scripts, Linear-B, Mycenaean/Danaic Greek, decipherment software

\section{Introduction}

The Linear-B script conveys Mycenaean/Danaic Greek, which is the oldest known form of written Greek (Babiniotis, 2002, p. 83). It was devised from the previous Aegean pre-alphabetic scripts (Cretan Hieroglyphics and Linear-A), although not in a simple manner of evolution (Davis, 2010), since it can be regarded as a relative of the previous Linear-A and not as a direct successor (Hooker, 2011, p. 55).

Inscriptions of Linear-B were firstly discovered at Knossos during the excavations by Sir A. Evans (Evans, 1909; 1952). The script was deciphered in 1952 by M. Ventris (Ventris \& Chadwick, 1973). The discovered inscriptions so far cover a period of approximately 300 years, from $1450 \mathrm{BC}$ to $1150 \mathrm{BC}$ (Babiniotis, 2002, p. 84; Andronikos, 1987). They have been found mainly on clay tablets, relatively few on vessels and sherds (Davis, 2010, p. 48), in the palatial areas of Crete (Knossos and Khania) and of Southern mainland Greece (Orchomenos, Thebes, Elefsis, Mycenae, Tiryns and Pylos) (Christidis, 2005, p. 64). The main part of the nearly 5000 inscriptions comes from Knossos (approx. 3000) and from Pylos (1400) (Babiniotis, 2002, p. 84). The Linear-B script had been used by a relatively small number of scribes, at least 111 different "hands" (namely handwritings; see Hooker, 2011, p. 90), probably forming a guild of courtier bureaucrats in the Achaean palaces (Hooker, 1979; Finkelberg, 1998, p. 270).

The linguistic importance of Linear-B is significant for Comparative and Historical Linguistics, because it allows the study of the dynamics of an Indo-European language (Greek) for thirty-five centuries (since the $15^{\text {th }}$ century $\mathrm{BC})$. The texts reveal, as well, many social, cultural and commercial practices/features of the prehistoric Aegean civilizations (Duhoux \& Morpurgo Davies, 2008). The corpora are available from Sacconi (1974), Chadwick et al. (1986-1999), Bennett \& Olivier (1973-76) and Melena \& Olivier (1991).

\subsection{Linguistic Features}

The texts of Linear-B are of administrative nature, almost in their entirety, since the script was seemingly devised due to economic necessity (Hooker, 2011, p. 35). The main structure of the texts includes toponyms, anthroponyms, words and pictograms for registered items and signs for numbers (quantities), all of them arranged in catalogues. Because of the structure of these catalogues, the syntactic information concerning Mycenaean/Danaic Greek are very limited, although evidently Greek (Hooker, 2011, p. 132). 
The morphological features include nominal and verbal stems of Greek etymology, adverbial prepositions, prefixes, inflectional and derivational suffixes. A few well-known Greek inflectional classes are recognized, while the derivational suffixes are these morphemes that indicate a Greek language wherever the stem is not construed as

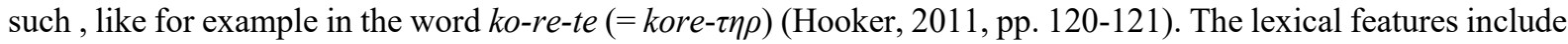
also the presence of names (anthroponyms and toponyms) that constitute at least $65 \%$ of the total number of words (Ventris \& Chadwick, 1973, p. 92). Very few of them can be undoubtedly construed as Greek.

The Linear-B script is a syllabary, augmented with pictograms for items and signs for numbers. The syllabic signs (syllabograms) have the phonetic values of the patterns $\mathrm{V}$ (for a single vowel) and $\mathrm{CV}$ (for a pair of consonantvowel), representing an open syllable, which are very improper for the Greek phonotactics, where clusters of two to four consonants can be frequently encountered, as well as closed syllables with final consonants. This particular feature increases the difficulty of deciphering and interpreting the encountered words, despite the set of spelling rules that had been devised by the scribes, introducing various kinds of misconceptions. Few examples are presented in the next section.

\subsection{Literature Review}

The scale of difficulty for studying Linear-B texts is evident by the suggested spelling errors of the scribes that are found since the prehistoric times on the tablets. In Hooker (2011) there are at least eleven occasions of spelling errors or of wrong etymology observed (Hooker, 2011, pp. 101-102, 106, 109, 111, 113, 119, 124, 125, 132, 135, 251), made by the professional scribes of the Achaean courts. The interpretation is additionally obstructed by the script itself (namely the spelling rules), which doesn't differentiate the phonetic values of most dental ([t], $[\theta]$ ), palatal ([k], [x], [g]), labial ([p], [f], [v], [b]) or liquid ([1], [r]) consonants (Babiniotis, 2002, p. 86). For instance, what is written as "ra" could also be a [la]. In this way, the number of syllabograms is reduced to ninety, considering two of them (No. 34 and No. 35) as mirror images of syllable "ni" (Kenanidis \& Papakitsos, 2018, p. 26). A consequence of this phonetic ambiguity though is the alternative interpretations, or the absence of them, in various cases of words and phrases. Three examples are quoted below.

\subsection{Interpretation Examples}

The tablet PY Tn 996 contains a record of bath vessels and items. The designation of a tablet includes the place of discovering it (PY = Pylos), the content group ( $\mathrm{Tn}=$ vessels) and a serial number (996). On this tablet, the word

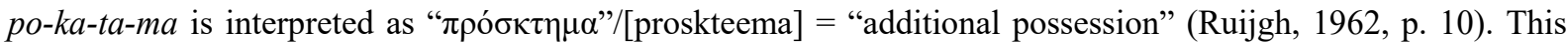
interpretation is both formally and semantically false. Semantically, the term "additional possession" is too vague for a list of specific bath-items. Formally, the prefix [pro(s)-] is implemented in Linear-B as po-ro (Hooker, 2011,

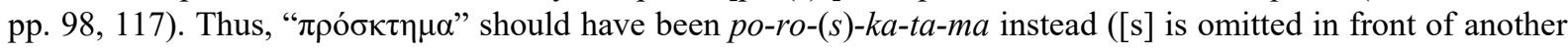
consonant). The herein suggested interpretation is the following:

- $\quad$ po-ka-ta-ma $>$ (derived from)

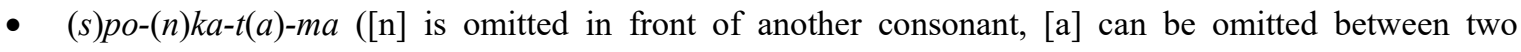
consonants when the accompanying vowel of the second consonant is the same one) $>$

- $\quad$ sponkatma $>$

- $\quad \operatorname{spongaa\theta ma}([\mathrm{k}]>[\mathrm{g}] ;[\mathrm{a}]>[\mathrm{aa}] ;[\mathrm{t}]>[\theta])>$

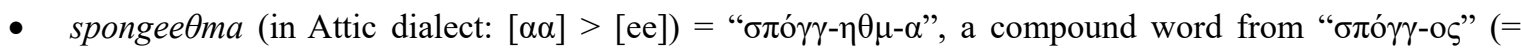
"sponge") and " $\eta \theta \mu$-ó $\varsigma$ " (= "strainer").

Thus, the suggested word is reconstructed according to the spelling rules of Linear-B, describing a sponge-strainer as a specific bath-item.

On the same tablet, the word a-sa-mi-to is interpreted as a piece of furniture (Varias Garcia, 2006), while the corresponding word " $\alpha \sigma \alpha \dot{\mu} \mu v \theta 0{ }^{\prime}$ " (= "bath-tub") is well known from Homer (Reece, 2002, p. 703) to mean the bath-tub (Francis, 1992, pp. 481, 491-492). Next to the word a-sa-mi-to is the pictogram of a bath-tub!

Another example of a dubious phrase is the one referring to tripods, which is repeated in many tablets, like PY Ta 641:

- ti-ri-po-de ai-ke-u ke-re-si-jo we-ke (Hooker, 2011, p. 211; Ventris \& Chadwick, 1973, p. 236; Palmer, 1963, p. 250).

The given interpretations have various discrepancies:

- The first word (ti-ri-po-de) stands for the tripod.

- The second one (ai-ke-u) probably denotes the name of the owner, the keeper or the manufacturer. 
- The last phrase (ke-re-si-jo we-ke) is repeated several times in the collection of the tablets relevant to tripods.

Three different possible interpretations have been suggested for the last phrase (Babiniotis, 2002, p. 87):

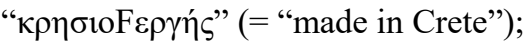

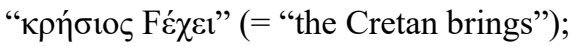

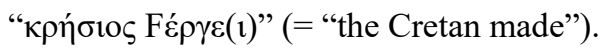

Interpretation (i) has to be excluded: It is presented as a single word, while on the tablet it is clear that there are two words, separated by the standard delimiter (a small vertical line). The rest of the interpretations refer to "Cretan"

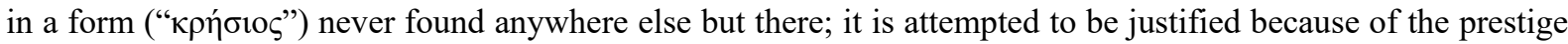
of the Cretan products (Hooker, 2011, p. 212). Yet, it looks like the wishful-thinking of the interpreter(s) to discover the name of Crete in Linear-B tablets. The name "Crete" is firstly encountered in Homer (e.g., see:

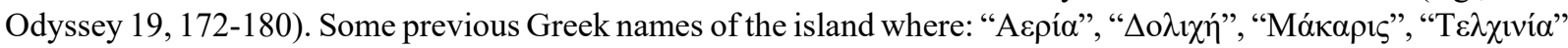
(Byzantii, 1839, p. 274). Other tripods that are described in this set of tablets include those with burned legs

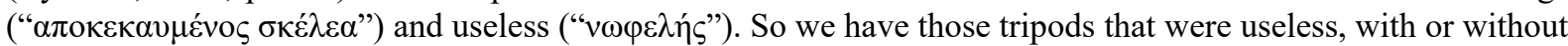
burned legs, and those made in Crete that are presumably imperishable! The herein suggested interpretation is:

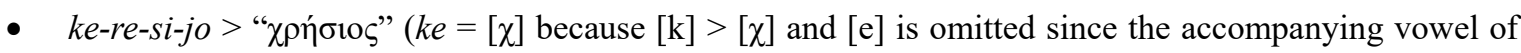

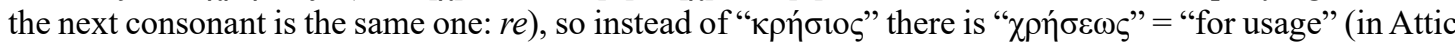
Greek dialect);

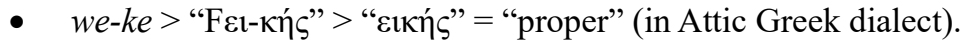

Thus, ke-re-si-jo we-ke = "proper for usage, usable" (unlike the useless ones also recorded on the same tablet).

These alternative interpretations motivated the present work: a software tool that can facilitate the interpretation of Linear-B tablets (texts) and one that will be also useful in learning Linear-B, as educational software for Greekspeaking undergraduate and postgraduate students of the Classics Departments, world-wide.

\section{Method}

The idea was the creation of a software tool that would allow its user to choose the syllabograms of a word (written in Linear-B) from a virtual keyboard (on screen). After clicking an "interpretation button", the program would return to the user one or more interpretations of the given word, retrieved from a lexicon (database) of Ancient Greek. Especially the Ancient Greek of Homer is the closest form to Mycenaean/Danaic Greek of the Linear-B tablets. The original purpose of this tool is to facilitate the reading of Linear-B tablets and not to write something into Linear-B script. Consequently, the reverse search function of choosing an Ancient Greek word and returning the possible syllabogram sequences is not supported.

\subsection{Project Analysis}

The three main modules of the required tool are: the database (lexicon), the search-engine and the interface (on screen). The software system was developed in two stages. At the first stage, the database was created as a spreadsheet file, using a digital dictionary of Ancient Greek (Symeonidis et al., 2010). An intermediate software tool transliterated the words of Ancient Greek into their equivalent Mycenaean/Danaic (Linear-B syllabic) form (Papamichail, 2012). At the second stage, the search-engine and the interface were developed (Kontogianni, 2014). Concerning the database, several online lexica of Linear-B are freely available, notably:

- Palaeolexicon (2008) is a digital database for many ancient languages. The Linear-B section includes the syllabic form, the Latin transliteration and an English translation. It does not include a Greek interpretation (neither Ancient nor Modern), making the relation of etymology difficult and timeconsuming for a Greek speaker.

- The Linear B lexicon of C. Tselentis (Tselentis, 2012) contains for every lemma: the syllabic form, the Latin transliteration, both the Greek and the English pronunciation and the English translation. Since it is found as a "pdf" file, it cannot be directly used as a database.

- The "Minoan Linear A and Mycencean Linear B" lexicon of Kim Raymoure (2013), contains a searchengine that returns the place where the tablet of the selected word was found, along with an English interpretation (mainly). Based on the work of Ventris \& Chadwick (1973), it requires renewal and enrichment. The Greek interpretation is rare.

- DĀMOS is a database of Mycenaean at Oslo (Aurora et al., 2013), aiming at the creation of a digital 
tagged corpus of all the published texts in Linear-B. It is useful for finding the tablets that the searched word is located. The searching ability is impressive but the visual representation is rather poor, mostly lacking the syllabic form, without interpretation, while the direct transliteration is frequently obscure.

- LiBER (Linear B Electronic Resources) is probably the most comprehensive database of Linear-B (MNAMON, 2016). It provides reach metadata, transcriptions, critical apparatus, photographs, interactive maps about find-spots, chronologies, scribes, inventory numbers and places of preservation. The optimum usage of this database requires on behalf of the user a significant amount of time to get familiar with the abilities of the searching tools.

The common characteristic of these databases is that to use them for learning and reading Linear-B scripts can be more cumbersome than using conventional tools, like an encyclopaedia, at least to the perception of the authors herein. The features of the previous lexica made a new design necessary, tailored to the next presented requirements. The desired features are the good coverage of the material, the presentation of a translation into Greek with etymology or comments and an easy to learn/use interface, suitable for undergraduate or postgraduate students of Classics.

\section{Results}

Consequently, the implementation of the design concerns the two main modules of the software system, which are visible to the users: the lexicon and the interface, the latter being the final result of the development process.

\subsection{The Lexicon}

An intermediate tool, encoded in Visual C\# 2008 computer programming language (e.g., see Foxall, 2008), transliterated automatically a digital dictionary of Ancient Greek (Symeonidis et al., 2010) into a spread-sheet file (Papamichail, 2012), containing every word in Ancient Greek along with the equivalent standard transliteration of

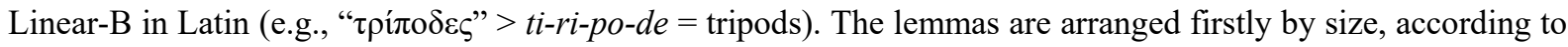
the number of their Latin-form syllables (e.g., tiripode $=4$ ) and then alphabetically. This particular arrangement facilitates a faster searching of the database by the search-engine. The computational transliteration was achieved through the reverse application of Linear-B spelling rules. This unsupervised process presented some inevitable shortcomings. For example, some phonemes of Mycenaean/Danaic Greek (e.g., [kw], [gw], [kwh]) were transformed to others in the post-Mycenaean/Danaic Greek (i.e., $\{\mathrm{p} ; \mathrm{t} ; \mathrm{k}\},\{\mathrm{b} ; \mathrm{d} ; \mathrm{g}\}$ or $\{\mathrm{ph} ; \mathrm{th} ; \mathrm{kh}\}$, respectively), according to the context. The reverse transformation could not been encoded. The obsolescence of the Ancient Greek phoneme "F" (= $[\mathrm{w}])$ could not be predicted, hence it was not re-inserted. On the contrary, the insertion of

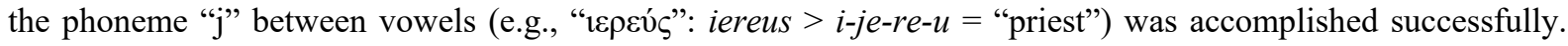
Notably, this particular insertion is encountered even nowadays, not only in the Cretan Greek dialect (e.g., "крı́ $\varsigma$ ":

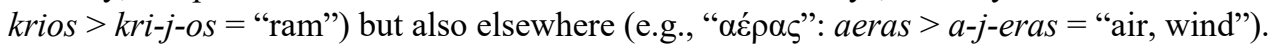

Obviously, the above shortcomings had to be corrected by hand. The original outcome (i.e., the database file) was corrected, modified and enriched in various ways by Kontogianni (2014), with the usage of the sources listed below:

- the Linear-B Lexicon of Tselentis (2012);

- the Palaeolexicon (2008);

- the online dictionary of Greek, from Enacademic (2000-2017);

- the online dictionary of Ancient Greek by Liddell \& Scott (1940);

- the dictionary of ancient mythological, historical and geographical proper names by Lorentis (1837);

- the word-list of Hooker (2011).

Eventually, from the initial 2,755 lemmas of the lexicon:

- 410 were corrected;

- 1,749 words in Linear-B were inserted;

- 170 entries were interpreted, having at least 350 interpretations;

- 315 words containing the phoneme " $F$ " were inserted;

- 50 words, initiating with [q], having an equivalent form in Ancient Greek, were inserted;

- 1,045 entries were tagged/commented. 
The present version contains 4,504 lemmas (Figure 1), each one consisting of the Linear-B syllabic transliteration in Latin, the Ancient Greek interpretation(s) and, wherever necessary, a commentary that includes: explanatory comments; a tagging as toponym, anthroponym, name of divinity, month or nation; the reference of the original source of the comments from the previous list. The contained information of the lexicon can be utilized through the interface of the software system, in a user-friendly manner.

\begin{tabular}{|c|c|c|}
\hline Transliteration: & Ancient Greek: & Comments: \\
\hline atewe & $\dot{\alpha} \tau \hat{\eta} F \varepsilon \imath$ & 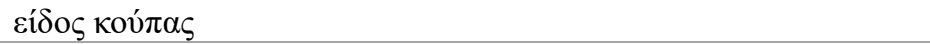 \\
\hline atija & 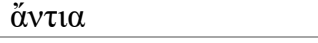 & 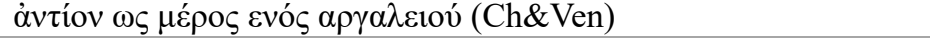 \\
\hline atuko & 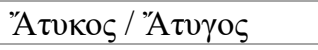 & $\alpha v \theta \rho \omega \pi \omega v v ́ \mu 10$ \\
\hline dajaro & $\Delta \alpha i ́ \alpha \rho \rho_{5}$ & 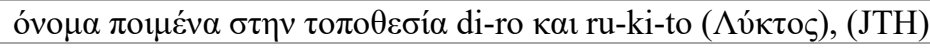 \\
\hline damate & 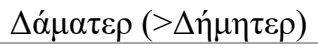 & 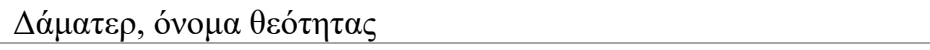 \\
\hline damate & $\delta \alpha ́ \mu \alpha \tau \varepsilon \varsigma$ & 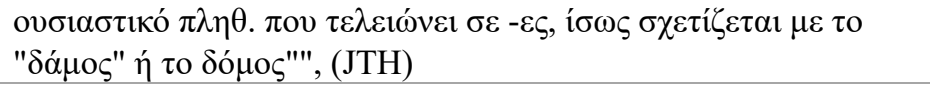 \\
\hline
\end{tabular}

Figure 1. A sample of the Linear-B Lexicon's content and structure

Note. Source: Kontogianni, 2014.

\subsection{The Interface}

The interface of the application is very simple to use (Appendix A). The entire user-guide is accessible on screen by clicking the "Help" button (Figure 2), on the right side of the window-screen. The Linear-B syllabograms of regular phonetic values are placed on a virtual keyboard in a grid on the left side of the window-screen ("Syllable Signs"). The icons are arranged according to the preceding consonants of the syllables, in rows, and according to the following vowel, in columns. The relevant consonants are arranged vertically on the left of the equivalent row, while the relevant vowels are arranged horizontally on top of the equivalent column. The first row of the grid contains the stand-alone vowels. At the bottom of the window-screen, the virtual keyboard is completed with a row of syllabograms of irregular phonetic values ("Special Signs"), appearing under each icon. Although fourteen of the syllabograms are considered to be of unknown or dubious phonetic value (Babiniotis, 2002, p. 85), the present arrangement assigns a suggested phonetic value to all of them, according to the recent classification by Kenanidis (2013).

The users may choose the syllabograms of a word by clicking on the relevant icon of the virtual keyboard. The sequence of the selected syllabograms appears on screen under the label "Linear B Word". Simultaneously, the Latin transliteration of the phonetic values appears under the label "Transliteration". If an icon is selected by mistake, it can be erased by clicking on the button "Correct", on the right side of the window-screen. The searchengine is activated by clicking on the button "Search", under the "Transliteration" place. If the word is found in the Lexicon, the Ancient Greek interpretation and the related commentary appears on the space under the "Search" button, else a failure-message is presented there. Then, the users may click on the button "Clear", on the right side of the window-screen, in order to repeat the search with a new word.

Various messages informing the user for false actions may appear on pop-up windows. By clicking on the last button "Exit", on the right column of the window-screen, the user may close the application and the session, alternatively to the standard " $\mathrm{x}$ " button on the upper right corner of the window-screen. The source of the Linear$\mathrm{B}$ tablet's icon is referenced by clicking on the icon. Finally and most importantly, the interpretation session is recorded in a text file that can be printed afterwards. In this way, the entire content of a tablet can be printed in an interpreted form, for facilitating learning or decipherment. 


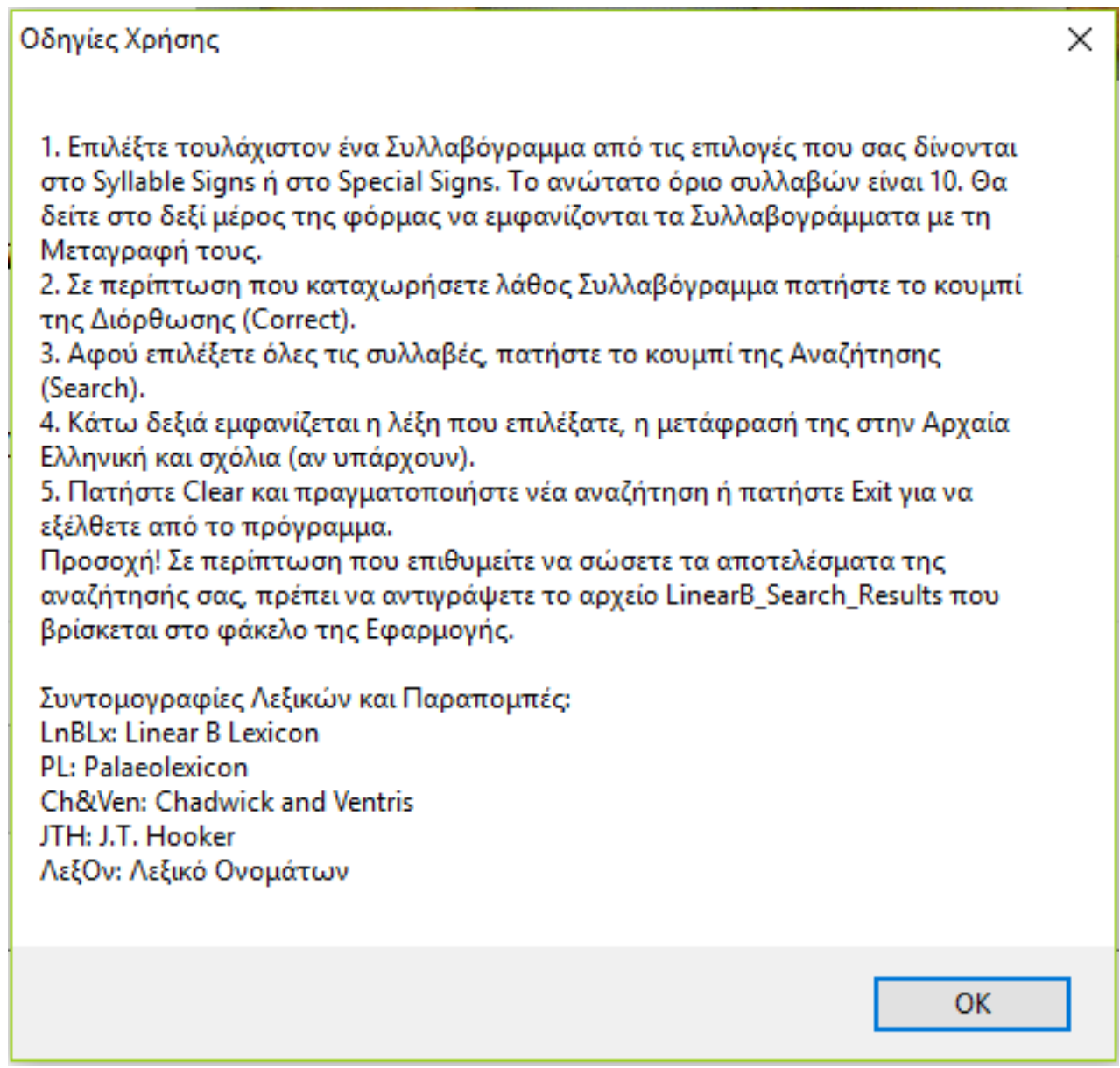

Figure 2. The user-guide window

Note. Source: Kontogianni, 2014.

\section{Discussion}

It would be probably interesting to report the various challenges that were encountered during the development of this particular software system and probably of similar ones, as well, under similar conditions. Most of the challenges were initially expected. Consequently, the development process was designed according to a systemic manner, following the relevant model of OMAS-III (Papakitsos, 2013). This particular model combines concepts of software engineering and communication theory, forming a unified working framework, for both software development and project management, with obvious organizational advantages. The respective studied factors had been: the resources and conditions, the required time and mode of implementation, as well as the required persons/experts for a successful implementation.

The first major challenge had been the complete luck of research funds (resources), mainly but not exclusively due to the economic crisis that harasses Greece, since 2010. Thus, the development project had to be carefully planned, in order to be implemented in a sequence of successive postgraduate dissertations (Papamichail, 2012; Kontogianni, 2014), under the same supervisor. The stages had to be of limited interaction, while the whole process spanned a time longer (more than double) than technically necessary.

Similar projects cannot be realized without an interdisciplinary approach (persons/experts). Four experts had been involved: a linguist, specialized in ancient scripts, and three linguistic computing engineers. The contribution of the linguist, as presented in subsection 1.3 Interpretation Examples, was crucial for defining the scope of the project. Yet, some comments about the notion of interdisciplinarity could be useful. Because of the prolonged development time and the relative isolation of the team members, since only two out of four were working simultaneously at any given time, interdisciplinarity was better applied by the same person. Namely, one of the experts was a software engineer, specialized in linguistic engineering/computing, and the other was a linguist 
specialized in computational linguistics. Needless to say that the supervisor had to be experienced in both disciplines, in order to connect the different parts together, having the overall picture of the project.

A final note regarding the results of linguistic software applications: as it is exhibited by the examples in subsection 3.1 The Lexicon, the more complicated a linguistic application is, the less unsupervised the software can be. Systems that transliterate text from one language (or form of language) to another (herein from Ancient to Mycenaean/Danaic Greek and vice-versa) should be better viewed as computer-assisted transliteration ones instead of a stand-alone/automated application. The involvement of humans is still indispensable, in various parts and tasks of the project, because language rules or phenomena cannot always be captured in an encodable manner. Another relevant example is presented in the next subsection, regarding the usage of this software tool as a decipherment model.

\subsection{Decipherment Models}

Some comments now about the computational efforts for deciphering ancient texts would be appropriate. There is a single work published by Snyder et al. (2010), created for a similar purpose. The opinion of the authors herein is that the work of Snyder et al. (2010) is technically not similar to this project in many (if not all) aspects. Yet, a presentation and comparison is useful, because these two models can be more complementary than competitive.

In a few words, Snyder et al. (2010) have developed a statistical model (henceforth S-Model) for the automatic decipherment of lost languages, tested on Ugaritic, a lost but known Western Semitic language of the $14^{\text {th }}$ century $\mathrm{BC}$, written in cuneiform consonantal alphabet (Pardee, 2008). The unsupervised software system that is implemented according to S-Model is based on the linguistic similarities of Ugaritic to Hebrew. This system uses an encoded dictionary of Hebrew. The S-Model performs matches of Hebrew words to Ugaritic ones, in order to discover the latter. The results have a remarkable recall accuracy of $90.53 \%$, denoting though that no matter how accurate a system is, it still requires some amount of human intervention for the rest of the text.

Let's proceed to the comparison. The S-Model is designed for unsupervised decipherment of lost-languages, while our lexical model (henceforth L-Model) for active transliteration and teaching of a lost language. S-Model requires a prior digitalization of the text, while L-Model is readily available. S-Model bases the successful decipherment on the existence and selection of another language (i.e., Hebrew) related to the lost one (i.e., Ugaritic). If such a related language is not correctly selected (or even exists) then the decipherment will fail. L-Model just interprets the text of the lost language (i.e., Mycenaean/Danaic Greek) in a more recent and also readable version (i.e., Ancient Greek). That is why the latter is also capable of being a teaching tool, which was one of the two initial goals of its development.

The present software system introduces a model (L-Model) for interpreting other existing corpora and teaching the conveyed languages, as well. For example, there are hundreds of thousands of cuneiform tablets existing (in Sumerian, Akkadian, etc.), but only about $10 \%$ of them have been interpreted so far, because there are very few experts globally (Watkins \& Snyder, 2003). Their interpretation could change History, as we know it. The development of similar software systems for this double purpose could assist significantly the laborious efforts of the involved scholars.

\subsection{Conclusions}

Although the Linear-B tablets are available for more than half a century, there are just a few academic books written in Greek about the Mycenaean/Danaic Greek (Pantelidis, 2012; Hooker, 2011; British Museum, 1987; Chadwick, 1962), a few databases and not a single relevant interactive software system for Greek speakers, up to now. The present one aims at facilitating the learning of Linear-B by Greek university students (or by other students of the Classics Departments world-wide, who can read Ancient Greek), as an auxiliary teaching tool. Since it is supported by a reach, recent and explanatory database of Linear-B in Greek, it can be also used for the study and interpretation not only of the existing Linear-B inscriptions but also of whatever might be discovered in future. Due to various limitations of the available infrastructure, this software tool is not web-based (for the time being), while because of its novelty there are no empirical results regarding the potential research and/or educational benefits from its usage.

The two most important future updates of the system include: the installation of other languages than Greek and the support of the Mycenaean/Danaic Greek inflectional morphology. The installation of other languages is technically easy, by adding to the Lexicon two new columns (for each new language), having the Ancient Greek word and the accompanying comments translated, respectively. In addition, a new button must be attached on the window-screen of the interface, for selecting the relevant language. The support of inflectional morphology is far more difficult. At the moment, the different inflected forms of a Greek word are registered as separate entries. 
Techniques similar to the existing ones for Modem Greek (Grigoriadou et al., 2004; Kornilakis et al., 2004; Papakitsos et al., 2002; Papakitsos, 2000) can be used to achieve this update.

\section{Acknowledgments}

The authors would like to express their thankfulness to Mrs. S. Kataki for the gratuitous typing of the text.

\section{References}

Andronikos, M. (1987). Mycenaean and Greek Script. Proceedings of the $8^{\text {th }}$ annual meeting of the Linguistics Sector of the Faculty of Philosophy of the Aristotle University of Thessalonica, 1-24. Thessalonica, Greece. (In Greek).

Babiniotis, G. (2002). Concise history of the Greek language (5th ed.). Athens, Greece: M. Romanos. (In Greek).

Bennett, E. L., \& Olivier, J. P. (1973-76). The Pylos Tablets Transcribed, vols. I-II. Rome: Edizioni dell'Ateneo.

British Museum. (1987). Linear B and Related Scripts. "Reading the Past" Series. (Translated into Greek by A. Konomi, Athens, Greece: Papadimas Publ., 1992).

Byzantii, S. (1839). E $\Theta N I K \Omega N$. Lipsiae, Germany: Antonius Westermann.

Chadwick, J., Godart, L., Killen, J. T., Olivier, J. P., Sacconi, A., \& Sakellarakis, J. A. (1986-1999). Corpus of Mycenaean Inscriptions from Knossos, vols. 1-V. Cambridge, England: Cambridge University Press; Rome, Italy: Edizioni dell'Ateneo.

Chadwick, J. (1962). Decipherment of Linear B. Athens, Greece: Kakoulidis Publ. (Translated into Greek by D. Tzortzidis; sold out).

Christidis, A. F. (2005). History of the ancient Greek language. Thessalonica, Greece: Institute of Modern Greek Studies. (In Greek).

Aurora, F., Nesøen, A., Nedić, D., Løken, H., \& Bersi, A. (2013). DAMOS - Database of Mycenaean at Oslo. Oslo, Norway: University of Oslo. Retrieved from https://www2.hf.uio.no/damos/

Davis, B. (2010). Introduction to the Aegean Pre-Alphabetic Scripts. KUBABA, 1, 38-61. Retrieved from http://projectos.fcsh.unl.pt/kubaba/Davis_2010_Introduction_to_Aegean_pre-Alphabetic_Scripts.pdf

Duhoux, Y., \& Morpurgo Davies, A. (Eds.) (2008). A Companion to Linear-B. Mycenaean Greek Texts and their World, Volume 1. Louvain-la-Neuve, Paris, France and Dudley, MA: Iditions Peeters.

Enacademic. (2000-2017). Academic Dictionaries and Encyclopedias: Morphologia Gr. Retrieved from http://morphologia_gr_en.enacademic.com/

Evans, A. J. (1909). Scripta Minoa: The Written Documents of Minoan Crete: with Special Reference to the Archives of Knossos. Volume I: The Hieroglyphic and Primitive Linear Classes: with an account of the discovery of the pre-Phoenician scripts, their place in the Minoan story and their Mediterranean relatives: with plates, tables and figures in the text. Oxford, England: Clarendon Press.

Evans, A. J. (1952). Scripta Minoa: The Written Documents of Minoan Crete: with special reference to the archives of Knossos. Volume II: The Archives of Knossos: clay tablets inscribed in linear script B: edited from notes, and supplemented by John L. Myres. Oxford, England: Clarendon Press.

Finkelberg, M. (1998). Bronze Age Writing: Contacts Between East and West. In E. H. Cline, \& D. Harris-Cline (Eds.), The Aegean and the Orient in the Second Millennium (pp. 265-272). Liège, Belgium: Cline \& HarrisCline.

Foxall, J. (2008). Teach Yourself Visual C\# 2008 in 24 Hours. USA: Pearson Education, Inc.

Francis, E. D. (1992). The impact of non-Indo-European languages on Greek and Mycenaean. In E. C. Polomé, \& W. Winter (Eds.), Trends in Linguistics: Reconstructing Languages and Cultures (Studies and Monographs 58). Berlin, Germany and New York, NY: Mouton de Gruyter.

Grigoriadou, M., Kornilakis, H., Galiotou, E., Stamou, S., \& Papakitsos, E. (2004). The Software Infrastructure for the Development and Validation of the Greek Wordnet. Romanian Journal of Information Science and Technology, 7(1-2), 89-105. Abstract retrieved from http://www.romjist.ro/content/grigoriadou.html

Hooker, J. T. (2011). Introduction to Linear-B (2nd ed.). Athens, Greece: MIET. (Translated into Greek from the original edition and augmented: Hooker, J. T., Linear B: An Introduction, Bristol Classical Press, 1980).

Hooker, J. T. (1979). The Origin of the Linear B Script. Minos Suppl., 8, 46-47. 
Kenanidis, I. K. (2013). Historical and Linguistic Studies: cwepeker. Kavala, Greece: E.P. Lazidou. (In Greek).

Kenanidis, I. K., \& Papakitsos, E. C. (2018). Seven Linear B Syllabograms of Conventionally Unknown Phonetic Value. International Linguistics Research, 1(2), 22-30. https://doi.org/10.30560/ilr.v1n2p22

Kontogianni, A. V. (2014). Research Software: Development of a Linear B Lexicon (Unpublished MSc dissertation). National \& Kapodistrian University of Athens and National Technical University of Athens, Athens, Greece. (In Greek).

Kornilakis, H., Grigoriadou, M., Galiotou, E., \& Papakitsos, E. (2004, January). Using a Lemmatizer to Support the Development and Validation of the Greek WordNet. Paper presented at the Second Global Wordnet Conference, Brno, Czech Republic.

Liddell, H. G., \& Scott, R. (1940). A Greek-English Lexicon. Oxford, England: Clarendon Press. Retrieved from http://www.perseus.tufts.edu/hopper/

Lorentis, N. (1837). Dictionary of ancient mythological, historical and geographical proper names. Vienna, Austria: A. Benkos. (In Greek). Retrieved from http://anemi.lib.uoc.gr/php/pdf_pager.php?rec=/metadata/b/0/7/metadata-39-

0000434.tklanddo $=109671$.pdfandlang $=$ enandpageno $=1$ andpagestart $=1$ andwidth $=426.24$ ptsandheight $=616.08$ ptsandmaxpage $=601 /$

Melena, J. L., \& Olivier, J. P. (1991). TITHEMY: The Tablets and nodules in Linear B from Tiryns, Thebes and Mycenae. Minos Supplement 12. Salamanca, Spain: Ediciones Universidad de Salamanca.

MNAMON. (2016). LiBER [Linear B Electronic Resources]. Pisa, Italy: Scuola Normale Superiore. Retrieved from http://liber.isma.cnr.it/cgi-bin/home.cgi

Palaeolexicon. (2008). Linear B. Retrieved from http://www.palaeolexicon.com/Linear B/

Palmer, L. R. (1963). The Interpretation of Mycenaean Greek Texts. Oxford, England: Oxford University Press.

Pantelidis, N. (2012). Linear B: Structure and writing rules. Athens, Greece: National \& Kapodistrian University of Athens . (In Greek).

Papakitsos, E. (2013). The Systemic Modeling via Military Practice at the Service of any Operational Planning. International Journal of Academic Research in Business and Social Science, 3(9), 176-190. https://doi.org/10.6007/IJARBSS/v3-i9/200

Papakitsos, E. C. (2000). Contribution to the Morphological Processing of Modern Greek: Functional Decomposition - Cartesian Lexicon (Doctoral dissertation). National \& Kapodistrian University of Athens, Athens, Greece. (In Greek).

Papakitsos, E., Grigoriadou, M., \& Philokyprou, G. (2002). Modelling a Morpheme-based Lexicon for Modern Greek. Literary and Linguistic Computing, 17(4), 475-490. https://doi.org/10.1093/1lc/17.4.475

Papamichail, C. A. (2012). Computational and Statistical Processing of the Phaestos Disk: Creation of the Database (Unpublished MSc dissertation). National \& Kapodistrian University of Athens and National Technical University of Athens, Athens, Greece. (In Greek).

Pardee, D. (2008). Ugaritic. In R. D. Woodard (Ed.), The Ancient Languages of Syria-Palestine and Arabia (pp. 5-6). New York, NY: Cambridge University Press. https://doi.org/10.1017/CBO9780511486890

Raymoure, K. (2013). Minoan Linear A and Mycenaean Linear B. Retrieved from http://minoan.deaditerranean.com/

Reece, S. (2002). The Homeric Ađó́ $\mu \imath v 0$ os: Stirring the Waters of the Mycenaean Bath. Mnemosyne, 55(Fourth Series, Fasc. 6), 703-708.

Ruijgh, C. J. (1962). Tabellae Mycenenses Selectae: Textus minores, vol.28. Leiden, Belgium: Brill.

Sacconi, A. (1974). Corpus delle iscrizioni vascolari in lineare B. Rome, Italy: Edizioni dell'Ateneo.

Snyder, B., Barzilay, R., \& Knight, K. (2010, July). A Statistical Model for Lost Language Decipherment. ACL '10 Proceedings of the 48th Annual Meeting of the Association for Computational Linguistics, 1048-1057. Uppsala, Sweden. Retrieved from https://dl.acm.org/citation.cfm?id=1858788

Symeonidis, C., Xenis, G., \& Fliatouras, A. (2010). Dictionary of Ancient Greek Language. Athens, Greece: Pedagogical Institute. (In Greek).

Tselentis, C. (2012). Linear-B-Lexicon. Retrieved from http://www.scribd.com/doc/56265843/Linear-B-Lexicon 
Varias Garcia, C. (2006). Observations on the Mycenaean Vocabulary of Furniture and Vessels. In "Pasiphae", Atti del XII Colloquio Internazionale di Micenologia, Vol. II (pp. 775-793). Roma, Italy.

Ventris, M. G. F., \& Chadwick, J. (1973). Documents in Mycenaean Greek (2nd ed.). Cambridge, England: Cambridge University Press.

Watkins, L., \& Snyder, D. (2003). The Digital Hammurabi Project. Baltimore, Maryland: Johns Hopkins University.

\section{Appendix A}

\section{The Interface of the Application}

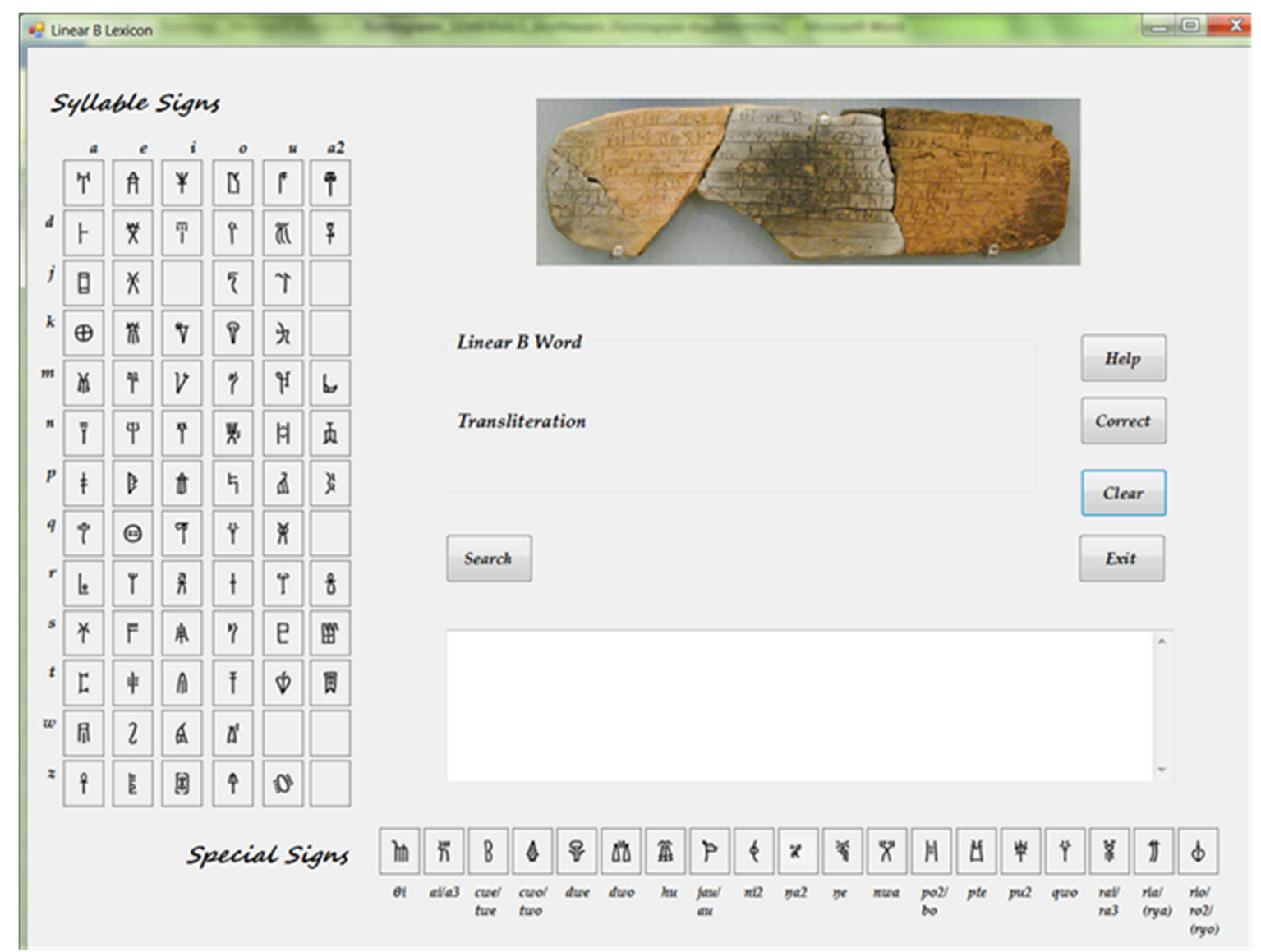

Note. Source: Kontogianni, 2014.

\section{Copyrights}

Copyright for this article is retained by the author(s), with first publication rights granted to the journal.

This is an open-access article distributed under the terms and conditions of the Creative Commons Attribution license (http://creativecommons.org/licenses/by/4.0/). 